\title{
Increased Prevalence of Anxiety-Associated Personality Traits in Patients with Cushing's Disease: A Cross-Sectional Study
}

\author{
C. Dimopoulou ${ }^{a} \quad$ M. Ising ${ }^{b} \quad$ H. Pfister ${ }^{b} \quad$ J. Schopohl ${ }^{c} \quad$ G.K. Stalla ${ }^{a} \quad$ C. Sievers ${ }^{a}$ \\ Departments of a Endocrinology and ${ }^{b}$ Molecular Psychology, Max Planck Institute of Psychiatry, and \\ ${ }^{\mathrm{C}}$ Medizinische Klinik Innenstadt, Ludwig-Maximilians-University, Munich, Germany
}

\section{Key Words}

Personality $\cdot$ Cushing's disease $\cdot$ Non-functioning pituitary adenomas

\begin{abstract}
Background/Aims: Chronic hypercortisolism in Cushing's disease (CD) has been suggested to contribute to an altered personality profile in these patients. We aimed to test this hypothesis and attempted to determine the effects of disease- and treatment-related factors that might moderate an altered personality in CD. Methods: We assessed 50 patients with CD (74\% biochemically controlled) and compared them to 60 patients with non-functioning pituitary adenomas (NFPA) and 100 age- and gender-matched mentally healthy controls. Personality was measured by two standardized personality questionnaires, TPQ (Cloninger Personality Questionnaire) and EPQ-RK (Eysenck Personality Questionnaire-RK). Results: Compared to mentally healthy controls, CD patients reported significantly less novelty-seeking behaviour, including less exploratory excitability and less extravagance. On harm avoidant subscales, they presented with more anticipatory worries and pessimism, higher fear of uncertainty, shyness with strangers, fatigability and asthenia. Moreover, CD patients appeared to be less extraverted, more neurotic and socially desirable. CD patients differed from NFPA patients in terms of higher neuroticism scores,
\end{abstract}

and NFPA patients did not show altered novelty-seeking behaviour or extraversion. In the subgroup analysis, CD patients with persistent hypercortisolism displayed significantly higher fear of uncertainty, fatigability and asthenia, indicating high harm avoidance in total, than those in biochemical remission. Conclusion: Patients with CD showed a distinct pattern of personality traits associated with high anxiety in combination with traits of low externalizing behaviour. Such personality changes should be taken into account in the diagnosis and treatment of CD patients, as they might interfere with the patient-physician communication and/or challenge the patients' social and psychological functioning.

Copyright $\odot 2012$ S. Karger AG, Basel

\section{Introduction}

Several studies have focussed on psychopathological and personality changes associated with pituitary lesions [1]. In our previous work [2], we reported increased anxiety-related personality traits in combination with reduced externalizing traits in patients with acromegaly compared to the general population. Patients with nonfunctioning pituitary adenomas (NFPA) also reported elevated anxiety-related traits in this study, while no differences were observed in externalizing traits.

\section{KARGER \\ Fax +4161306 1234}

E-Mail karger@karger.com

www.karger.com
(C) 2012 S. Karger AG, Basel

$0028-3835 / 13 / 0972-0139 \$ 38.00 / 0$

Accessible online at:

www.karger.com/nen
Christina Dimopoulou

Kraepelinstrasse 2-10

DE-80804 Munich (Germany)

Tel. +49893062 2460

E-Mail dimopoulou@mpipsykl.mpg.de 
A large number of studies in humans and animal models have documented the interaction of glucocorticoids and the central nervous system via the hippocampus [3], suggesting a glucocorticoid component in common psychiatric disorders such as anxiety, depression and insomnia [4-6]. Through these central effects, it is conceivable that in Cushing's disease (CD), a state of chronic hypercortisolism, personality might be altered.

Several previous studies have investigated personality dimensions in CD so far [7-12]. Anxiety seems to be more pronounced in patients with $\mathrm{CD}$ than in patients with adrenal causes of hypercortisolism, suggesting the importance of the pituitary mass per se [13]. After correction of hypercortisolism, psychopathology gradually improves [14]. However, comparable to long-term impairment of quality of life $[15,16]$, an increased prevalence of psychopathology and maladaptive personality traits persists even after long-term cure of $C D$, suggesting irreversible effects of previous glucocorticoid excess on the central nervous system rather than a direct effect of pituitary tumours and/or their treatment per se, as recently reported [9].

Since an anxiety-associated personality profile for $C D$ has been described, we aimed to verify this hypothesis and attempted to determine the effects of disease- and treatment-related factors that might contribute to these personality traits. To test this hypothesis, we employed two standardized personality questionnaires, the Cloninger Personality Questionnaire (TPQ) and the short version of the revised Eysenck Personality QuestionnaireRK (EPQ-RK) [2]. To exclude the possibility that pituitary adenomas and/or their treatment are associated with anxiety-associated personality traits, we contrasted CD patients against a clinical control group with NFPA and age- and gender-matched mentally healthy controls.

\section{Subjects and Methods}

\section{Participants}

Ninety-two patients with previously diagnosed CD treated at the Max Planck Institute of Psychiatry and the Medizinische Klinik Innenstadt, Ludwig-Maximilians-University, were invited to participate in this study (response rate 54\%). As a clinical control group, we recruited 60 patients with NFPA treated previously by transsphenoidal surgery (response rate 60\%). As a mentally healthy control group, we sampled 100 age- and gender-matched controls (ratio 1:2) recruited within the Munich Antidepressants Response Signature project. Since matching for age could not be exact, we considered a number of \pm 3 years acceptable for a match. Absence of a history of mental disorders was verified with a modified version of the Munich-Composite-Diagnostic Interview
[17], and absence of severe internal diseases was evaluated with a structured interview and by questionnaire. All subjects gave their written informed consent. The study was approved by the local ethical committee.

\section{Assessment of Personality}

Personality traits in the three study groups were assessed using two questionnaires, the German versions of the EPQ-RK and the TPQ.

The EPQ-RK comprises 50 items to be answered in a binary mode as 'yes'/'no' [18]. The responses define three independent personality dimensions: (i) psychoticism defined as cold, impersonal, lacking in sympathy, emotionality, empathy and insight combined with a tendency of paranoid ideas against oneself; (ii) extraversion characterized by enjoyment of social interactions and in novel activities and a tendency towards impulsive behaviour, and (iii) neuroticism defined by feelings of anxiety, depressed mood and guilt. These personality dimensions are complemented by a social desirability scale evaluating the tendency to respond in a manner that is assumed to be viewed favourably by others.

The TPQ encompasses 100 items describing statements about habitual behaviour, which can be answered in a binary mode as 'I do agree'/ 'I do not agree' [19]. The responses are summarized with respect to three dimensions of personality: novelty seeking (TPQ-NS) representing the heritable tendency toward exploratory activity and intense excitement to novel stimuli, harm avoidance (TPQ-HA) as heritable tendency to respond intensively to aversive stimuli and to learn to avoid punishment, and novelty and situations of non-reward and reward dependence (TPQ-RD) reflecting the heritable tendency to respond intensively to reward and succorance and to learn to maintain rewarded behaviour. These personality dimensions can be further subdivided into subscales, which are (i) exploratory excitability (TPQ-NS1), impulsiveness (TPQ-NS2), extravagance (TPQ-NS3) and disorderliness (TPQ-NS4) within the novelty-seeking dimension; (ii) anticipatory worries and pessimism (TPQ-HA1), fear of uncertainty (TPQ-HA2), shyness with strangers (TPQ-HA3) and fatigability and asthenia (TPQ-HA4) within harm avoidance, and (iii) sentimentality (TPQ-RD1), persistence (TPQ-RD2), attachment (TPQ-RD3) and dependence (TPQ-RD4) within reward dependence.

The EPQ-RK and TPQ show substantial correlations between some subscales such as novelty seeking and extraversion $(\mathrm{r}=0.53)$, suggesting representation of a common trait of externalizing behaviour; also, harm avoidance and neuroticism correlate with each other $(\mathrm{r}=0.6)$, describing a common trait of an anxiety-related personality [20].

\section{Assessment of Comorbidities, Biochemical Variables and} Covariates

Clinical characteristics of the subjects were collected with regard to disease history, tumour characteristics, previous and current therapy, and comorbidities as well as current complaints. Comorbidities were diagnosed and treated according to the respective guidelines.

Diagnosis of CD was confirmed by histological examination following transsphenoidal exploration of the pituitary. Therapies used to treat CD followed the current consensus treatment algorithm [21]. Transsphenoidal surgery with selective pituitary tu- 
mour resection represented the treatment of choice. Second-line treatments included more radical surgery, radiation therapy, medical therapy and bilateral adrenalectomy.

Diagnostic criteria suggestive of hypercortisolism after treatment for CD were (a) urinary free cortisol level greater than the normal range for the assay, and (b) serum cortisol greater than 1.8 $\mathrm{g} / \mathrm{dl}(50 \mathrm{nmol} / \mathrm{l})$ after $1 \mathrm{mg}$ dexamethasone [22]. Thirteen patients (26\%) did not fulfil the criteria of biochemical control at study time point.

Pituitary function was assessed in both patient groups at yearly intervals and a maximum of \pm 3 months in relation to the timing of the questionnaires. Evaluation of pituitary function comprised basal fasting measurements of IGF1, TSH, free thyroxine, total triiodothyronine, $\mathrm{LH}, \mathrm{FSH}$, prolactin and testosterone (in men) or oestradiol (in women) in all patients, as well as stimulation tests such as a short ACTH test or the GHRH/arginine test in the case of suspected pituitary deficiencies in the corticotropic or somatotropic axis [23]. All CD patients with secondary hypoadrenalism, hypothyroidism, hypogonadism and hyposomatotropism $(56,42,20$ and 28\%, respectively) and all NFPA patients with secondary hypoadrenalism, hypothyroidism, hypogonadism and hyposomatotropism $(44,43,38$ and $43 \%$, respectively) were studied while on optimized replacement therapy [23]. In the case of hypoadrenalism, this included substitution with $10-25 \mathrm{mg}$ hydrocortisone per day (2-3 doses per day).

\section{Statistical Analysis}

Statistical analysis was performed using SPSS Version 17 for Windows. Sample characteristics were compared using $\chi^{2}$ tests and analysis of variance. Differences in personality between CD patients, mentally healthy controls and the clinical control group of NFPA patients were evaluated with an analysis of covariance (ANCOVA) controlling for age, gender, arterial hypertension and diabetes mellitus, characteristics that differed between the three groups. In the case of group differences, post hoc tests, corrected for multiple comparisons following the Bonferroni-Holm procedure, were applied (level of significance 0.05 ). In addition, we applied ANCOVA controlling for age and gender to evaluate personality differences between biochemically controlled and uncontrolled CD patients, between hypopituitary patients and patients with normal pituitary function, between radiated and non-radiated CD patients or dependent on disease duration ( $>$ median vs. $<$ median). Differences were considered statistically significant at $\mathrm{p}<0.05$. Missing values for single questions about clinical comorbidity were changed into zero, hypothesizing that patients involved most likely did not experience this symptom or comorbidity. Missing values in the personality questionnaires were estimated by the respective individual scale mean (if the number of missing items is not exceeding $10 \%$ ).

\section{Results}

\section{Demographic and Clinical Characteristics of the Study Group}

In the CD patient group ( $\mathrm{n}=50,82 \%$ female), the mean age was $46.36 \pm 11.63$ years. The majority of the CD patients (38\% with microadenomas) had been previously operated (98\%; mean time after surgery $115.2 \pm 14.7$ months). Thirteen patients (26\%) were irradiated and 5 patients received medical treatment with ketoconazole (10\%). The mean time after radiotherapy was $84.1 \pm 17.4$ months. CD patients suffered from pituitary deficiency (64\%), arterial hypertension (60\%), arthralgia (50\%), diabetes mellitus (22\%) and arrhythmias (18\%). CD was biochemically controlled in 37 patients (74\%) at the time of the study. The mean time after biochemical remission was $85.75 \pm 39.0$ months. The mean actual 24-hour urinary free cortisol was $213.6 \pm 63.4 \mu \mathrm{g}$ (reference range for the used assay $20.9-292.3 \mu \mathrm{g} / 24 \mathrm{~h}$ ).

CD patients differed from NFPA patients in gender, age, adenoma type and comorbidities. Compared to NFPA patients, there were significantly more female CD patients (82 vs. $35 \%$; $\mathrm{p}<0.001$ ). CD patients were significantly younger $(46.4 \pm 11.6$ vs. $60.2 \pm 10.6$ years; $p<$ 0.001 ), with a lower prevalence of macroadenomas (20 vs. $83 \%$; $<<0.001$ ).

Table 1 presents demographic and clinical characteristics of the study groups.

\section{Profile of Personality Traits in CD Patients Compared to Mentally Healthy Control Subjects and NFPA Patients}

Compared to mentally healthy controls, CD patients reported significantly less novelty-seeking behaviour (TPQ-NS; $\mathrm{p}<0.001$ ), which can be described by low exploratory excitability (TPQ-NS1; $\mathrm{p}<0.001)$ and low extravagance (TPQ-NS3; $\mathrm{p}=0.015$ ). On harm avoidant subscales, CD patients presented with more anticipatory worries and pessimism (TPQ-HA1; $\mathrm{p}<0.001$ ), higher fear of uncertainty (TPQ-HA2; $p<0.001$ ), shyness with strangers (TPQ-HA3; $\mathrm{p}<0.001$ ), and fatigability and asthenia (TPQ-HA4; $\mathrm{p}<0.001$ ), indicating high harm avoidance in total (TPQ-HA; $\mathrm{p}<0.001$ ). CD patients did not appear to be more reward dependent in total (TPQ$\mathrm{RD} ; \mathrm{p}>0.05)$; moreover, there were no significant differences between the two groups in the subscales sentimentality, persistence, attachment or dependence. Regarding the three personality dimensions as defined by the EPQ$\mathrm{RK}, \mathrm{CD}$ patients appeared to be more neurotic (EPQ-N; $\mathrm{p}<0.001)$ and socially desirable (EPQ-SD; $\mathrm{p}=0.040)$, but less extraverted (EPQ-E; $\mathrm{p}=0.003)$ when compared to a mentally healthy population.

Elevated scores in harm avoidance (TPQ-HA; p < 0.001 ), social desirability (EPQ-SD; $p<0.001$ ) and neuroticism (EPQ-N; $\mathrm{p}<0.001)$ could also be documented in NFPA patients when compared to the mentally healthy control subjects. No differences were observed for nov- 
Table 1. Demographic and clinical characteristics of the study groups including 50 CD patients, 100 age- and gender-matched mentally healthy controls and 60 NFPA patients

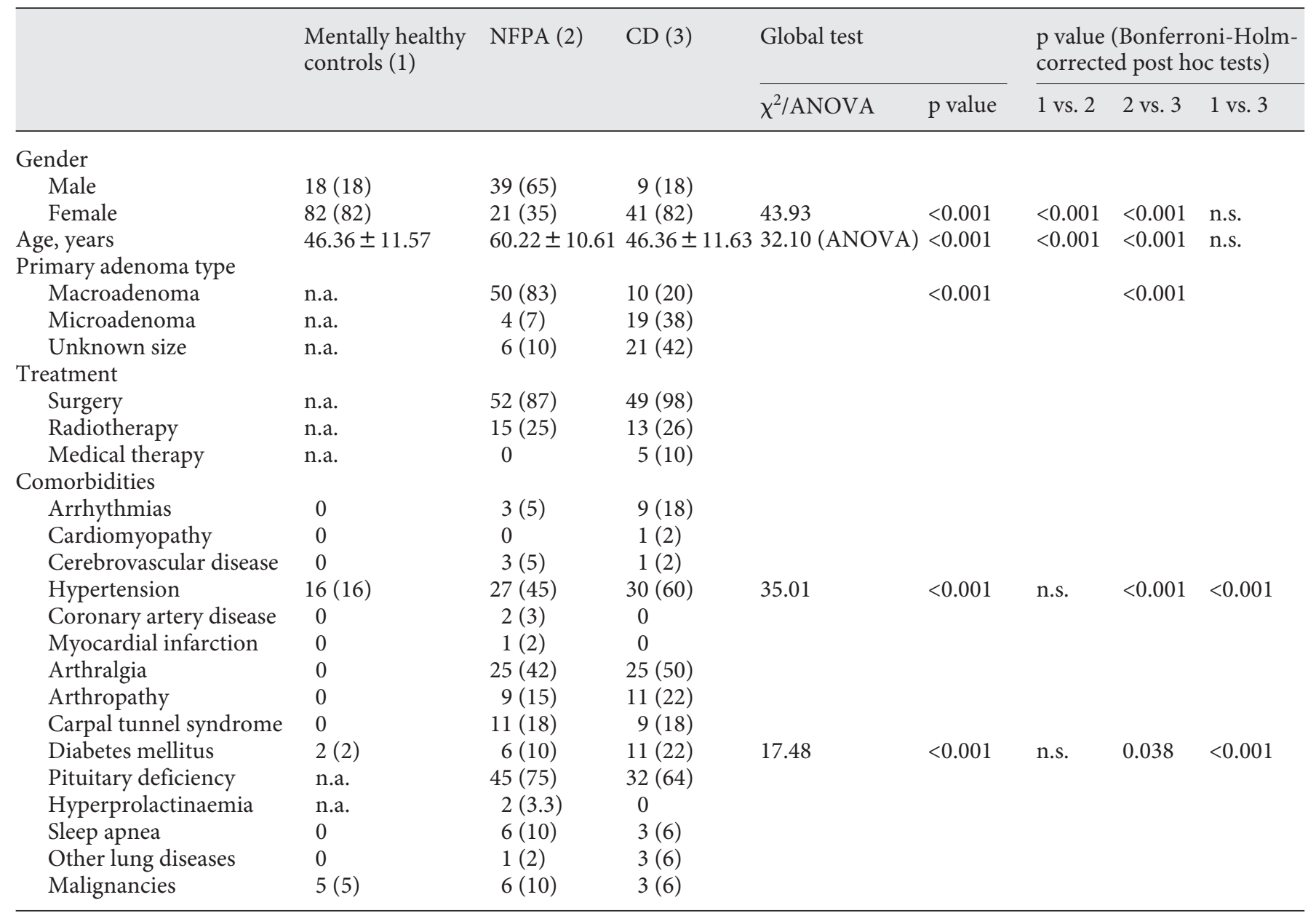

Values are means \pm SD or numbers with percentages in parentheses. n.s. $=$ Nonsignificant; n.a. $=$ not applicable.

elty seeking (TPQ-NS) and extraversion (EPQ-E), while $\mathrm{CD}$ patients presented with reduced scores on these scales when compared with mentally healthy controls. Specific differences for $\mathrm{CD}$ patients were found with respect to neuroticism (EPQ-N), with the highest scores observed in $\mathrm{CD}$, followed by significantly lower scores in NFPA patients $(\mathrm{p}=0.003)$, which still were higher than those observed in mentally healthy controls $(\mathrm{p}<0.001)$.

Table 2 presents personality traits of the study groups.

\section{Subgroup Analysis of Patients with CD}

To evaluate personality differences between biochemically controlled and uncontrolled CD patients, between hypopituitary patients and patients with normal pituitary function, between radiated and non-radiated CD patients or dependent on disease duration ( $>$ median vs. $<$ median), we additionally applied ANCOVA controlling for age and gender. Since chronic pain might be a factor altering the patients' personality profile, we additionally conducted a subgroup analysis in patients with and without arthralgia.

CD patients with persistent cortisol excess presented with significantly higher fear of uncertainty (TPQ-HA2; $\mathrm{p}=0.008)$ and fatigability and asthenia (TPQ-HA4; $\mathrm{p}=$ 0.034 ), indicating high harm avoidance in total (TPQ$\mathrm{HA} ; \mathrm{p}=0.036$ ) when compared with biochemically controlled CD patients. Furthermore, hypopituitary patients appeared to be more shy with strangers (TPQ-HA3; p = 0.011 ) in comparison to patients with normal pituitary function. No further statistically significant differences $(p<0.05)$ could be detected in any of these comparisons. 
Table 2. Personality traits of the study groups

\begin{tabular}{|c|c|c|c|c|c|c|c|}
\hline \multirow{2}{*}{$\begin{array}{l}\text { Mentally } \\
\text { healthy } \\
\text { controls (1) }\end{array}$} & \multirow[t]{2}{*}{ NFPA (2) } & \multirow[t]{2}{*}{$\mathrm{CD}(3)$} & \multicolumn{2}{|c|}{ ANCOVA } & \multicolumn{3}{|c|}{$\begin{array}{l}\mathrm{p} \text { value (Bonferroni-Holm } \\
\text { corrected post hoc tests) }\end{array}$} \\
\hline & & & $F(2,18)$ & p value & 1 vs. 3 & 2 vs. 3 & 1 vs. 2 \\
\hline
\end{tabular}

\section{$T P Q$}

TPQ novelty seeking total (TPQ-NS)

TPQ harm avoidance total (TPQ-HA)

$16.45 \pm 4.4513 .49 \pm 4.8313 .74 \pm 3.997 .60$

$10.33 \pm 5.48 \quad 15.63 \pm 6.81 \quad 19.94 \pm 6.6935 .36$

0.001

$<0.001$ n.s. n.s.

TPQ reward dependence total (TPQ-RD)

TPQ exploratory excitability (TPQ-NS1)

$17.32 \pm 4.2915 .56 \pm 3.6917 .44 \pm 4.040 .34$

$\begin{array}{lllll}4.71 \pm 1.71 & 3.65 \pm 1.83 & 3.48 \pm 1.75 & 6.83\end{array}$

TPQ impulsiveness (TPQ-NS2)

TPQ extravagance (TPQ-NS3)

$3.87 \pm 1.76 \quad 3.44 \pm 2.12 \quad 3.30 \pm 1.95 \quad 2.63$

$\begin{array}{llll}4.31 \pm 1.54 & 3.37 \pm 1.50 & 3.74 \pm 1.76 & 4.32\end{array}$

$\begin{array}{llll}3.56 \pm 1.68 & 3.00 \pm 1.57 & 3.24 \pm 1.36 & 0.87\end{array}$

$<0.001$

$<0.001$ n.s.

$<0.001$

TPQ disorderliness (TPQ-NS4)

TPQ anticipatory worries

and pessimism (TPQ-HA1)

TPQ fear of uncertainty (TPQ-HA2)

TPQ shyness with strangers (TPQ-HA3)

TPQ fatigability and asthenia (TPQ-HA4)

$3.08+2.12 \quad 4.25+2.49 \quad 5.68+2.19 \quad 22.95$

n.s.

n.s. n.s. n.s.

$0.001<0.001$ n.s. n.s.

n.s. n.s. n.s. n.s.

0.0150 .015 n.s. n.s.

n.s. n.s. n.s. n.s.

$\begin{array}{lllll}3.32 \pm 1.87 & 4.40 \pm 1.82 & 5.30 \pm 1.62 & 15.15 & <0.001\end{array}$

$\begin{array}{lllll}2.14 \pm 1.71 & 2.82 \pm 1.86 & 3.62 \pm 1.69 & 8.95 & <0.001\end{array}$

$1.78 \pm 1.70 \quad 4.14 \pm 2.66 \quad 5.34 \pm 3.01 \quad 36.58$

$\begin{array}{llll}3.88 \pm 1.23 & 3.95 \pm 1.17 & 4.22 \pm 0.86 & 1.79\end{array}$

$3.74 \pm 2.10 \quad 3.54 \pm 1.86 \quad 4.24 \pm 2.03 \quad 1.32$

$6.70 \pm 2.64 \quad 5.70 \pm 2.28 \quad 6.08 \pm 2.30 \quad 0.90$

$3.00 \pm 1.35 \quad 2.37 \pm 1.41 \quad 2.92 \pm 1.61 \quad 0.20$

$<0.001$

n.s.

n.s.

n.s.

n.s.

$<0.001$ n.s. $\quad<0.001$

$<0.001$ n.s. 0.002

$<0.001$ n.s. n.s.

$<0.001$ n.s. $<0.001$

TPQ persistence (TPQ-RD2)

TPQ attachment (TPQ-RD3)

$\begin{array}{llll}3.00 \pm 1.35 & 2.37 \pm 1.41 & 2.92 \pm 1.61 & 0.20\end{array}$

\section{$E P Q-R K$}

EPQ-RK psychoticism (EPQ-P)

EPQ-RK extraversion (EPQ-E)

EPQ-RK neuroticism (EPQ-N)

EPQ-RK social desirability (EPQ-SD)

\begin{tabular}{rrrlr}
$1.96 \pm 1.68$ & $1.34 \pm 1.46$ & $1.60 \pm 1.46$ & 1.24 & \multicolumn{1}{c}{ n.s. } \\
$7.55 \pm 3.32$ & $5.91 \pm 3.84$ & $5.32 \pm 3.68$ & 5.21 & 0.006 \\
$2.84 \pm 2.20$ & $4.02 \pm 2.80$ & $6.48 \pm 3.39$ & 29.67 & $<0.001$ \\
$3.20 \pm 2.42$ & $5.76 \pm 2.75$ & $4.04 \pm 2.42$ & 7.40 & 0.001
\end{tabular}

n.s. n.s. n.s.

n.s. n.s. n.s.

n.s. n.s. n.s.

n.s. n.s. n.s.

Values are means \pm SD. Results of the EPQ-RK and the TPQ are compared between groups using ANCOVA controlling for age, gender, arterial hypertension and diabetes mellitus. Bonferroni-Holm-corrected post hoc tests for two-group comparisons are performed in the case of significant differences in the global ANCOVA. n.s. = Nonsignificant.

\section{Discussion}

We aimed to verify the observation that an anxietyassociated personality profile exists for $\mathrm{CD}$ and attempted to determine factors that might contribute to these personality traits. To address this issue, we employed two standardized personality questionnaires. To exclude the possibility that pituitary adenomas per se and/or their treatment might be associated with anxiety-related personality traits, we employed a clinical control group comprising NFPA patients.

This study demonstrates that CD patients are characterized by a pattern of elevated anxiety-related personality traits, TPQ harm avoidance and EPQ-RK neuroticism, in combination with reduced scores in externalizing traits, TPQ novelty seeking and extraversion. This is a typical pattern we have previously observed in acromegalic patients [2], while NFPA patients serving as clinical control group described themselves by lower - albeit still elevated - neuroticism scores and reported unchanged scores in externalizing traits compared with the mentally healthy controls.

Our results are in accordance with the recently published findings by Tiemensma et al. [9], who observed prevalence of 'maladaptive' traits in CD, even after longterm cure. In agreement with these findings, we observed elevated scores in anxiety-related traits as well as reduced scores in externalizing traits, which corresponds to higher scores on social avoidance as reported by Tiemensma et al. [9]. As anticipated, anxiety-related personality traits including higher scores on harm avoidance in total, but also on the subscales fear of uncertainty and fatigability and asthenia, were clearly associated with persistent cortisol excess.

Regarding treatment- and disease-related factors that might contribute to the observed personality profile, we did not observe any significant differences between radiated and non-radiated CD patients or dependent on dis- 
ease duration ( $>$ median vs. $<$ median; $p>0.05$ ), suggesting $\mathrm{CD}$ per se as the underlying cause of the observed traits. Hypopituitarism was positively associated with higher shyness with strangers as measured by the corresponding subscale of the TPQ. Tiemensma et al. [9] comparably reported a positive correlation between hypopituitarism and suspiciousness, but also between additional radiotherapy and hydrocortisone dependency with identity problems and between longer duration of remission and higher scores on the self-harm subscale. Furthermore, negative illness perceptions might contribute to an impaired quality of life in patients after long-term remission of $\mathrm{CD}$, as recently stated by Tiemensma et al. [9]; however, we did not investigate this systematically [24].

We can only speculate as to why CD patients exhibit the reported pattern of elevated anxiety traits (harm avoidance and neuroticism) in combination with reduced externalizing traits (novelty seeking and extraversion). A possible explanation could be an impaired cortical or subcortical integrity due to the chronic cortisol excess in $\mathrm{CD}$, which might translate into an altered personality pattern as observed in our study. This speculation is supported by the finding of cerebral atrophy and decreased hippocampal volume in CD patients [25]. Especially the hippocampal region has been discussed to be linked with $\mathrm{CD}$ as both a target for the deleterious effects of chronic glucocorticoid exposure cortisol and a region modulating the personality. Martin et al. [26] have been able to show a positive correlation between externalizing behaviour traits in terms of experience seeking and hippocampus volume, and particularly with the anterior portion of the right hippocampal grey matter. When taking into account that the observation of reduced externalizing traits in terms of low novelty seeking and extraversion was specific for $\mathrm{CD}$, one might speculate that changes in these traits might be a potential endophenotype for hippocampal impairment due to chronic glucocorticoid excess.

As a limitation of our study, we have to mention the cross-sectional design, which limits the possibility to draw conclusions on causal interferences between CDassociated changes and the development of an altered personality. Furthermore, we have to take into consideration that state variables such as depression, which is common in $\mathrm{CD}$, might have influenced personality trait assessment. Depression data are, unfortunately, not available. However, the personality questionnaires applied in this study have been designed for being robust against state effects to give a reliable picture of stable personality traits.

In conclusion, $\mathrm{CD}$ patients show a distinct pattern of personality traits associated with high anxiety in combination with traits of low externalizing behaviour, comparable with acromegalic patients, but only in part with NFPA patients. Persistent cortisol excess and the presence of hypopituitarism, but not previous radiation therapy or duration of active hypercortisolism, were partially associated with this personality profile. The reported personality pattern might constitute an additional challenge for diagnosis and therapy of $\mathrm{CD}$, and might contribute to impaired social and psychological functioning and well-being.

\section{Acknowledgements}

We thank Stefanie Held and Sylvia Lang for their valuable contribution in helping to process the patient data.

\section{Disclosure Statement}

C.D. and H.P. have nothing to declare. M.I. has been a consultant to MSD Merck. J.S. received lecture fees from Pfizer Pharma $\mathrm{GmbH}$, Ipsen International $\mathrm{GmbH}$ and Novartis Pharma GmbH. G.K.S. and C.S. were supported by a research grant from Pfizer Pharma GmbH, Karlsruhe, Germany. G.K.S. received lecture fees from Pfizer Pharma GmbH, Karlsruhe, Germany, Novo Nordisk Pharma GmbH, Germany, Ipsen International GmbH, Germany, and Novartis Pharma GmbH, Germany. C.S. received lecture fees from Pfizer Pharma GmbH, Karlsruhe, Germany, and Novartis Pharma GmbH, Germany.
References iety-related traits: comparison of 70 acromegalic patients with patients with non-functioning pituitary adenomas and age- and gender-matched controls. Eur J Endocrinol 2009; 160:367-373. diagnostic process. Exp Clin Endocrinol Diabetes 2000;108:480-485.

2 Sievers C, Ising M, Pfister H, Dimopoulou C, Schneider HJ, Roemmler J, Schopohl J, Stalla GK: Personality in patients with pituitary adenomas is characterized by increased anx-
3 Fietta P, Delsante G: Central nervous system effects of natural and synthetic glucocorticoids. Psychiatry Clin Neurosci 2009;63: 613-622. 
4 Chrousos GP, Kino T: Glucocorticoid action networks and complex psychiatric and/or somatic disorders. Stress 2007;10:213-219.

5 Boyle MP, Brewer JA, Funatsu M, Wozniak DF, Tsien JZ, Izumi Y, Muglia LJ: Acquired deficit of forebrain glucocorticoid receptor produces depression-like changes in adrenal axis regulation and behavior. Proc Natl Acad Sci USA 2005;102:473-478.

$\checkmark 6$ Chrousos GP, Kino T: Intracellular glucocorticoid signaling: a formerly simple system turns stochastic. Sci STKE 2005;2005:pe48.

7 Starr AM: Personality changes in Cushing's syndrome. J Clin Endocrinol Metab 1952;12: 502-505.

$>8$ Sonino N, Bonnini S, Fallo F, Boscaro M, Fava GA: Personality characteristics and quality of life in patients treated for Cushing's syndrome. Clin Endocrinol (Oxf) 2006; 64:314-318

$>9$ Tiemensma J, Biermasz NR, Middelkoop HA, van der Mast RC, Romijn JA, Pereira AM: Increased prevalence of psychopathology and maladaptive personality traits after long-term cure of Cushing's disease. J Clin Endocrinol Metab 2010;95:E129-E141.

10 Sablowski N, Pawlik K, Ludecke DK, Herr mann HD: Aspects of personality in patients with pituitary adenomas. Acta Neurochir (Wien) 1986;83:8-11.

-11 Loosen PT, Chambliss B, DeBold CR, Shelton R, Orth DN: Psychiatric phenomenology in Cushing's disease. Pharmacopsychiatry 1992;25:192-198.

-12 Sonino N, Ruini C, Navarrini C, Ottolini F, Sirri L, Paoletta A, Fallo F, Boscaro M, Fava GA: Psychosocial impairment in patients treated for pituitary disease: a controlled study. Clin Endocrinol (Oxf) 2007;67:719726 .
13 Mazet P, Simon D, Luton JP, Bricaire H: Psychic symptoms and personality of 50 patients with Cushing's syndrome (author's transl) (in French). Nouv Presse Med 1981;10:25652570.

-14 Dorn LD, Burgess ES, Friedman TC, Dub bert B, Gold PW, Chrousos GP: The longitudinal course of psychopathology in Cushing's syndrome after correction of hypercortisolism. J Clin Endocrinol Metab 1997;82 912-919.

15 Lindsay JR, Nansel T, Baid S, Gumowski J, Nieman LK: Long-term impaired quality of life in Cushing's syndrome despite initial improvement after surgical remission. J Clin Endocrinol Metab 2006;91:447-453.

16 Heald AH, Ghosh S, Bray S, Gibson C, Anderson SG, Buckler H, Fowler HL: Longterm negative impact on quality of life in patients with successfully treated Cushing's disease. Clin Endocrinol (Oxf) 2004;61:458465.

17 Wittchen HU, Pfister H: DIA-X-Interviews: Manual für Screening-Verfahren und Interview. Frankfurt, Swets \& Zeitlinger, 1997.

18 Ruch W: Die revidierte Fassung des Eysenck Personality Questionnaire und die Konstruktion des deutschen EPQ-R bzw. EPQRK. Zeitschrift für Differentielle und Diagnostische Psychologie 1999;20:1-14.

19 Weyers P, Krebs H, Janke W: Reliability and construct validity of the German version of Cloninger's tridimensional personality questionaire. Pers Individ Diff 1995;19:853-861.
20 Krebs H, Weyers P, Janke WV: Validation of the German version of Cloninger's TPQ: replication and correlations with stress coping, mood measures and drug use. Pers Individ Diff 1998;24:805-814.

21 Biller BM, Grossman AB, Stewart PM, Melmed S, Bertagna X, Bertherat J, Buchfelder M, Colao A, Hermus AR, Hofland LJ, Klibanski A, Lacroix A, Lindsay JR, NewellPrice J, Nieman LK, Petersenn S, Sonino N, Stalla GK, Swearingen B, Vance ML, Wass JA, Boscaro M: Treatment of adrenocorticotropin-dependent Cushing's syndrome: a consensus statement. J Clin Endocrinol Metab 2008;93:2454-2462.

22 Nieman LK, Biller BM, Findling JW, NewellPrice J, Savage MO, Stewart PM, Montori VM: The diagnosis of Cushing's syndrome: an endocrine society clinical practice guideline. J Clin Endocrinol Metab 2008;93:15261540.

-23 Schneider HJ, Aimaretti G, KreitschmannAndermahr I, Stalla GK, Ghigo E: Hypopituitarism. Lancet 2007;369:1461-1470.

24 Tiemensma J, Kaptein AA, Pereira AM, Smit JW, Romijn JA, Biermasz NR: Negative illness perceptions are associated with impaired quality of life in patients after longterm remission of Cushing's syndrome. Eur J Endocrinol 2011;165:527-535.

25 Simmons NE, Do HM, Lipper MH, Laws ER Jr: Cerebral atrophy in Cushing's disease. Surg Neurol 2000;53:72-76.

26 Martin SB, Covell DJ, Joseph JE, Chebrolu H, Smith CD, Kelly TH, Jiang Y, Gold BT: Human experience seeking correlates with hippocampus volume: convergent evidence from manual tracing and voxel-based morphometry. Neuropsychologia 2007;45:28742881. 